\title{
Effect of Changes in Crystalline Structure on the Infrared Absorption Spectrum of Cellulose
}

\author{
Florence H. Forziati and John W. Rowen
}

\begin{abstract}
The absorption spectra of native, mercerized, and amorphous celluloses are recorded for the region from 2 to 16 microns. Cellulose having the X-ray diffraction pattern of the native, or type I, crystal lattice is represented in this study by bacterial cellulose, cotton fibers, Valonia cell wall, and the residue from the hydrolysis of cotton linters. Cellulose having the X-ray diffraction pattern of the mercerized, or type II, crystal lattice is represented by regenerated cellulose, the residue from the methanolysis of mercerized cotton linters, and mercerized bacterial cellulose. Amorphous cellulose was obtained by milling the residue from the hydrolysis of cotton linters in a vibratory ball mill.

The spectra of the type I celluloses showed sharper and more clearly defined absorption bands than the spectra of the type II celluloses. The most striking differences were found in the 7- to 8- and 9- to 10-micron regions. In the former region of the spectrum of type I celluloses, definite absorption maxima of nearly equal intensity were found at approximately 7.0, 7.3, 7.4, and 7.5 microns. In the spectrum of type II celluloses, the maximum at 7.4 microns was lacking, while the absorption at 7.3 microns was considerably more intense than that at 7.0 and 7.5 microns. Observations in the 7 - to 8-micron region of the spectrum of the amorphous cellulose were prevented by the use of a suspending medium that absorbed in that region. In the 9- to 10-micron region, definite absorption maxima were found at approximately 9.0,9.4, and 9.6 microns with the type I celluloses. When cellulose I was converted into cellulose II or amorphous cellulose, these maxima merged into a single broad band. Conversion of cellulose I into cellulose II or amorphous cellulose also resulted in an increase in the intensity of the absorption at 11.2 microns. Although factors other than decrease in type I crystallinity may contribute to these changes in absorption characteristics, the changes may prove useful in evaluating changes in crystalline structure of cellulose.
\end{abstract}

\begin{abstract}
1 A report of work done under cooperative agreement with the United States Department of A griculture and authorzed by the Research and Marketing Act. The work is being supervised by the Southern Regional Research Laboratory zed by the Research and Marketing Act. The work is being
of the Bureau of Agricultural and Industrial Chemistry.
\end{abstract}

\section{Introduction}

Absorption bands associated with crystal structure are frequently found in the infrared spectra of crystalline substances $[1,2,3] .^{2}$ Accordingly, the possibility that native cellulose (type I crystal lattice), mercerized cellulose (type II crystal lattice), and amorphous cellulose might differ in spectral characteristics was considered during preliminary work on the infrared absorption of cellulose. A comparison of the spectra of regenerated cellulose films and mineraloil slurries of cotton ground in a Wiley mill to pass a 200-mesh screen, cotton that had been completely converted to the amorphous form by milling in the vibratory ball mill [4], and mercerized cotton ground in a Wiley mill to pass a 200 -mesh screen failed to reveal any significant differences. 'Therefore, it was assumed that the crystalline and amorphous forms of cellulose were identical with respect to infrared absorption. Later observations on the infrared absorption of a variety of celluloses, however, led to further consideration of this point and to the conclusion that cellulose I shows certain spectral characteristics not shown by cellulose II and amorphous cellulose. These characteristics and the observations that led to their recognition are discussed in this paper.

\footnotetext{
2 Figures in brackets indicate the literature references at the end of this paper.
}

\section{Materials and Methods}

The cellulosic materials used in this study were regenerated cellulose films, bacterial cellulose films, Empire cotton fibers, the cell wall of the unicellular alga, Valonia ventricosa, ${ }^{3}$ and the residues from the hydrolysis and methanolysis [5] of purified and mercerized cotton linters, ${ }^{4}$ respectively. The regenerated films were obtained by deacetylation of cellulose acetate [6]. The films of bacterial cellulose were produced by the growth of Acetobacter xylinum ${ }^{5}$ on a medium, recommended by Aschner [7], that contained 4 percent of sucrose. The films were harvested at intervals of 2 or 3 days, washed in water, and freed from nitrogenous material by storage in 5 -percent sodium hydroxide for 3 to 4 days. In order to prevent oxidation of the cellulose, this treatment was carried out in an atmosphere of nitrogen. The purified films were washed, allowed to stand in 0.5 -percent acetic acid for $30 \mathrm{~min}$, and washed until neutral to litmus. They were dried on chromiumplated or glass plates, then loosened at the edge with a razor blade and carefully stripped from the plate.

3 The authors are indebted to Wanda K. Farr of the Celanese Corp. of America for the Valonia ventricosa.

4 Richard E. Reeves of the Southern Regional Research Laboratory of the U. S Department of Agriculture kindly supplied the residues from the hydrolysis and methanolysis of purified and mercerized cotton linters.

${ }_{5}$ Cultures of Acetobacler xylinum were given us by G. A. Greathouse and H. G. Shirk of the National Research Council. 
The cotton was purified by the procedure recommended by the Southern Regional Research Laboratory of the U. S. Department of Agriculture [8]. A mat of parallel fibers several fibers in thickness was prepared, cut to the appropriate size, and mounted dry in a liquid-type absorption cell equipped with rock salt windows separated by a silver spacer $50 \mu$ thick, and having two screw cap closures. In order to reduce scattering of radiant energy, infrared transmitting liquids such as carbon disulfide, carbon tetrachloride, and mineral oil were placed in the cell when absorption measurements were made. Volatile liquids were removed from the cell with a stream of air, while liquids such as mineral oil were washed out with a volatile liquid. By following this procedure, it was possible to use the same mat of fibers with a series of liquids.

Large sections were cut from the cell walls of Valonia ventricosa that had been preserved for several years in 70-percent alcohol containing 1.4 percent of formalin. The fragments of wall were washed with water, then mounted and dried on the silver chloride window of an absorption cell. A second window was used to hold the dried fragments in position during the absorption measurements.

Samples of bacterial cellulose and of the residue from the hydrolysis of purified cotton fibers were mercerized for $10 \mathrm{~min}$. with 25 -percent sodium hydroxide at $25^{\circ}$ to $28^{\circ} \mathrm{C}$, conditions within the range shown by Sisson and Saner [9] to give complete mercerization of cotton.

Absorption measurements were made on mineraloil slurries of the cellulose powders, that is, the residue from the methanolysis of mercerized cotton linters and the residue from the hydrolysis of purified cotton linters both before and after mercerization and after milling in the vibratory ball mill [4]. The slurries were prepared by thoroughly mulling $50 \mathrm{mg}$ of sample in $0.25 \mathrm{ml}$ of mineral oil between weighted ground glass plates. Two absorption cells were used with each shurry. One contained a laver of slurry of capillary thickness; the other a layer approximately $25 \mu$ thick.

The spectra were obtained with a double beam automatic-recording Baird spectrophotometer [10] equipped with a sodium choloride prism. The performance of the instrument was checked frequently against a polystyrene film of known spectral characteristics. No attempt was made to compensate for the absorption of suspending media. Consequently, in those cases in which a suspending medium was used, the regions of the spectrum in which the medium absorbs are obscured. Dotted lines are used in the figures to represent these regions.

X-ray diffraction patterns obtained with a Geiger counter spectrometer with copper radiation, $\lambda=1.54050 \mathrm{~A}$, were used to identify the crystal lattice of the samples.

\section{Results and Discussion}

In figure 1 are shown the infrared absorption spectra of four samples of cellulose showing the
X-ray diffraction pattern of cellulose I (native cellulose) and two samples showing the X-ray diffraction pattern of cellulose II (mercerized cellulose). The former group consists of a film of bacterial cellulose, lavers of parallel cotton fibers, fragments of the cell wall of the unicellular alga, Valonia ventricosa, and the residue from the hydrolysis of cotton linters. The samples showing the X-ray diffraction pattern of cellulose II are a film of regenerated cellulose and the residue from the methanolysis of mercerized cotton linters.

A comparison of the spectra of bacterial (F621) and regenerated (F591) cellulose films shows that the absorption bands of bacterial cellulose are, in general, sharper and more clearly defined than the corresponding bands of regenerated cellulose. The difference between the two spectra is most striking in the 7- to 8-and 9- to $10-\mu$ regions. In the former region of the spectrum of bacterial cellulose, definite absorption maxima of nearly equal intensity are found at approximately $7.0,7.3,7.4$, and $7.5 \mu$. In the spectrum of regenerated cellulose, the maximum at $7.4 \mu$ is missing, while the absorption at $7.3 \mu$ is considerably more intense than that at 7.0 and $7.5 \mu$. In the 9- to $10-\mu$ region, definite absorption maxima occur in the spectrum of bacterial cellulose at approximately $9.0,9.4$, and $9.6 \mu$. A single broad band showing poorly defined shoulders at essentially these same wavelengths is found in the spectrum of regenerated cellulose. The spectra also differ with respect to the intensity of the absorption band at $11.2 \mu$. Examination of a large number of spectrograms obtained with the two types of films showed this band to be less intense in the spectrum of bacterial cellulose.

The spectrograms obtained with layers of parallel cotton fibers (F354, F357) and with fragments of the cell wall of Valonia (F309) are inferior to those obtained with bacterial cellulose. Nevertheless, these spectra show clearly the same characteristics between 7.0 and $7.5 \mu$ as the spectrum of bacterial cellulose. A definite band at approximately $9.0 \mu$ is also evident. Because of excessive scatternig, observations at longer wavelengths were of no value.

Both hydrolysis and alcoholysis attack the amorphous regions of cellulose, thereby lowering the degree of polymerization and increasing the degree of crystallinity of the residual cellulose [11, 5]. Such decreases in degree of polymerization as are indicated by the cuprammonium fluidities of these residues would not be expected to result in changes in infrared absorption. Accordingly, the spectra of the residues obtained by such treatment of cotton linters (F444A) and mercerized cotton linters (F257) may be considered to be essentially the spectra of cellulose I and cellulose II, respectively. Unfortunately, the absorption of the mineral oil in which these residues were suspended for infrared absorption measurements obscures the 7 - to $8-\mu$ region of the spectrum. In the 9 - to $10-\mu$ region, three absorption maxima are found in the spectrum of the residue from the hydrolysis of cotton linters. The location of these maxima is essentially the same 


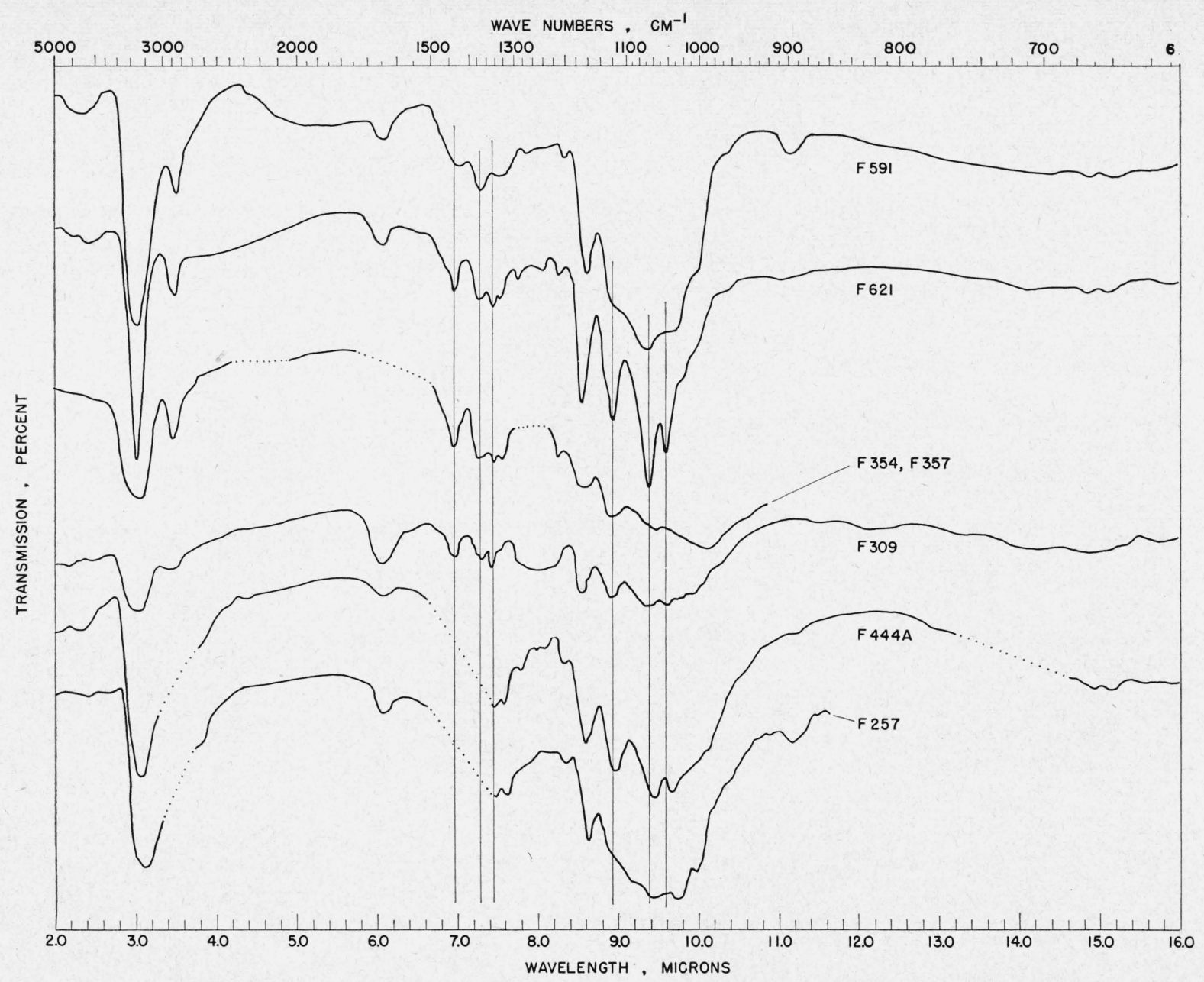

Figure 1. Infrared absorption spectra.

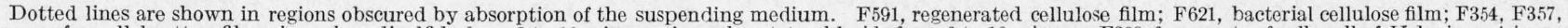

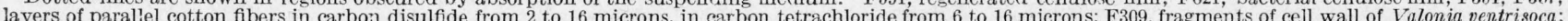
$\mathrm{F} 444 \mathrm{~A}$, residue from hydrolysis of cotton linters in mineral-oil slurry; F 257, residue from methanolysis of mercerized cotton linters in mineral-oil slurry.

as that of the maxima in the spectrum of bacterial cellulose. The spectrum of the residue from the methanolysis of mercerized linters shows a single broad band in this region. The spectra of the residues from cotton linters $(\mathrm{F} 444 \mathrm{~A})$ and mercerized cotton linters (F257) resemble, respectively, those of bacterial and regenerated cellulose with respect to the intensity of the absorption band at $11.2 \mu$.

Cellulose $\mathrm{I}$ is converted by mercerization to cellulose II, and by vibratory ball milling to amorphous cellulose. Hence, the effect of these treatments on the infrared absorption of bacterial cellulose and the residue from the hydrolysis of cotton linters is of interest. In figure 2, spectra obtained from mercerized bacterial cellulose and from the mercerized residue from the hydrolysis of cotton linters are presented. Also included in this figure are spectra that show the effect of milling in the vibratory ball mill for $15 \mathrm{~min}$. and 1 hour on the residue from the hydrolysis of cotton linters. As expected, the spectrum of the mercerized bacterial cellulose (F456) closely resembles that of regenerated cellulose (fig. 1, F591). The spectra of the mineraloil slurries of the mercerized (F462) and vibratory ball-milled samples (F536, F559) of the residue from the hydroloysis of cotton linters, like those of mercerized bacterial cellulose, regenerated cellulose, and the residue from the methanolysis of mercerized linters show a single broad band in the 9 - to $10-\mu$ region.

The foregoing observations suggest that resolution into absorption maxima at approximately 9.0, 9.4, and $9.6 \mu$ is peculiar to celluloses that show the X-ray diffraction pattern of cellulose I. Conversion of cellulose I into cellulose II or into amorphous cellulose spreads these maxima into a region of general absorption with poorly defined shoulders at these wavelengths. ${ }^{6}$ The presence of a single broad band in the 9- to $10-\mu$ region, however, is not proof of the absence of cellulose I. Thus, cotton that has been milled in the Wiley mill to pass a 200-mesh screen

${ }^{6}$ During the course of this work, it was learned that Stanley C. Burket [12] and Richard M. Badger of the California Institute of Technology had observed these same maxima in the spectrum of cellulose from the marine animal, Ciona intestinalis. They also found that mercerization resulted in decreased resolution. 


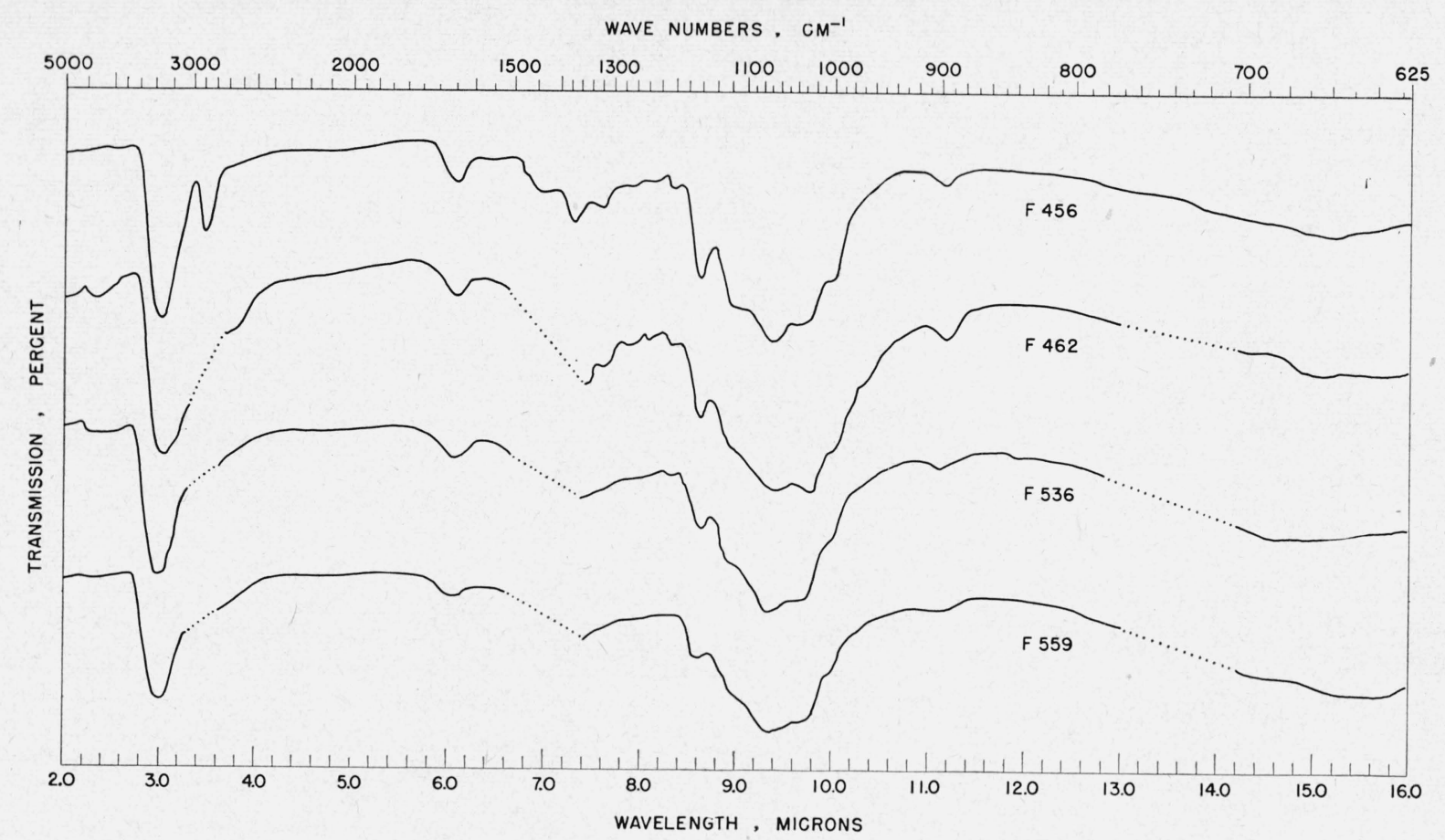

Figure 2. Infrared absorption spectra.

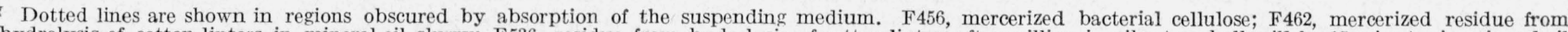

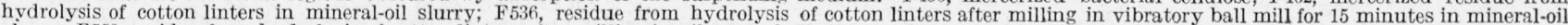
slurry; F 559, residue from hydrolysis of cotton linters after miniing in vibratory ball mill for 1 hour in mineral-oil slurry.

gives the X-ray diffraction pattern of cellulose I but fails to show the three distinct absorption maxima in the 9 - to $10-\mu$ region. Whether the failure to secure resolution is attributable to the amorphous material in the milled sample [13] or to some other factor is not known. The fact that better resolution is obtained with bacterial cellulose films than with mineral-oil slurries of the residue of the hydrolysis of cotton linters indicates that the sharpness of the bands in the 9- to $10-\mu$ region is not determined solely by the proportion of cellulose I present. Nevertheless, the possibility of using changes in the 9 - to $10-\mu$ region of the absorption spectrum of cellulose as a measure of change in the degree of crystallinity (type I) merits further investigation.

Because of the absorption of the mineral oil used in the infrared absorption measurements on cellulose powders, observations in the 7 - to 8 - $\mu$ region were limited to films and cotton fibers. These observations indicate, however, that mercerization and regeneration of cellulose result in a change in the intensity of the absorption at approximately 7.3 and $7.4 \mu$, as well as in a general broadening of absorption bands.

Some of the absorption bands observed with native cellulose have not been previously reported in the literature. Accordingly, a complete list of the bands found in infrared absorption spectra of bacterial cellulose films is shown in table 1. Suggestions as to the identity of the bands are also included in the table. These suggestions are based on published interpretations of spectra of other compounds.
TABLE 1. Infrared absorption spectrum of bacterial cellulose

\begin{tabular}{|c|c|c|c|c|}
\hline $\begin{array}{l}\text { Wave- } \\
\text { length }\end{array}$ & $\begin{array}{c}\text { Wave } \\
\text { number }\end{array}$ & Intensity & Tentative assignments & Related reference \\
\hline & $\mathrm{cm}^{-1}$ & & & \\
\hline 3. 01 & 3,320 & Strong & $\mathrm{OH}$ stretching. & [15] \\
\hline 3.48 & 2,870 & Medium _. & $\mathrm{CH}$ stretching & {$[15,16]$} \\
\hline 6. 09 & 1,640 & $\ldots$ do ..... & $\begin{array}{l}\text { HOH bending (ad- } \\
\text { sorbed water). }\end{array}$ & {$[17]$} \\
\hline 6.95 & 1,440 & do & $\mathrm{HCH}$ deformation .... & {$[15,18,19,20]$} \\
\hline 7. 30 & 1,370 & .... do & & \\
\hline 7.45 & 1,340 & ..... do & CH bending .... & {$[15,16]$} \\
\hline $\begin{array}{l}7.55 \\
7.78\end{array}$ & 1,325 & Wedo & (n) & - \\
\hline $\begin{array}{l}7.78 \\
7.99\end{array}$ & $\begin{array}{l}1,285 \\
1,250\end{array}$ & Weak & $\mathrm{CH}$ rocking in ring & [21] \\
\hline 8.10 & 1,235 & _..... do ... & & \\
\hline 8.30 & 1,205 & ..... do & CO stretching & [15] \\
\hline 8.55 & 1,170 & Strong & Ring frequency & {$[6,14,21,22,23]$} \\
\hline 8.95 & 1,115 & .... do & $\mathrm{COC}$ & [19] \\
\hline 9.38 & 1,065 & _..... do & $\mathrm{OH}$ bending & {$[15,18,19,21]$} \\
\hline 9.60 & 1,045 & do & $\mathrm{C}-\mathrm{OH}$ stretching ..... & [19] \\
\hline 9.80 & 1,040 & Weak.. & & \\
\hline 9.95 & 1,005 & _.... do & & \\
\hline 11. 20 & 894 & ..... do & & - \\
\hline
\end{tabular}

\section{Conclusions}

The results indicate that conversion of cellulose I into cellulose II or amorphous cellulose produces a decrease in the sharpness and definition of the infrared absorption spectrum, as well as changes in the intensity of absorption at certain wavelengths. Cellulose $\mathrm{I}$ is characterized by absorption maxima of nearly equal intensity at approximately 7.0, 7.3, 7.4, and $7.5 \mu$, whereas cellulose II shows maxima at $7.0,7.3$, and $7.5 \mu$. Of these maxima, that at $7.3 \mu$ is considerably more intense than those at 7.0 and $7.5 \mu$. No observations were made in this region of 
the spectrum of amorphous cellulose. With cellulose I, clearly defined absorption maxima are found at approximately 9.0, 9.4, and $9.6 \mu$. On conversion to cellulose II, these maxima merge into a single broad band with poorly defined shoulders at these wavelengths. Conversion to cellulose II or amorphous cellulose also results in an increase in the intensity of the absorption at $11.2 \mu$.

The authors express their appreciation to Earle K. Plyler for many helpful suggestions, Howard E. Swanson for the X-ray diffraction measurements, Sanford B. Newman and Emil Borysko for preparation of the bacterial cellulose, and Walter K. Stone for technical assistance.

\section{References}

[1] H. W. Thompson and P. Torkington, Trans. Faraday Soc. 41, 246 (1945)

[2] G. B. B. M. Sutherland and H. A. Willis, Trans. Faraday Soc. 41, 289 (1945).

[3] R. B. Barnes, R. C. Gore, E. F. Williams, S. G. Linsley, and E. M. Peterson, Anal. Chem. 19, 620 (1947).

[4] F. H. Forziati, W. K. Stone, J. W. Rowen, and W. D. Appel, J. Research NBS 45, 109 (1950) RP2116.

[5] R. E. Reeves, W. M. Schwartz, and J. E. Gliddens, J. Am. Chem. Soc. 68, 1383 (1946).
[6] J. W. Rowen, C. M. Hunt, and E. K. Plyler, J. Research NBS 39, 133 (1947) RP1816.

[7] M. Aschner, J. Bact. 33, 249 (1937).

[8] R. E. Reeves, Private communication.

[9] W. A. Sisson and W. R. Saner, J. Phys. Chem. 45, 717 (1941).

[10] W. S. Baird, H. M. O'Bryan, G. Ogden, and D. Lee, J. Opt. Soc. Am. 37, 754 (1947),

[11] G. F. Davidson, J. Text. Inst. 34, T87 (1943).

[12] S. C. Burket, PhD Thesis (California Institute of Technology, June 1950).

[13] M. L. Nelson and C. M. Conrad, Textile Research J. 18, 155 (1948).

[14] R. Steele and E. Pacsu, Textile Research J. 19, 790 (1949).

[15] R. B. Barnes, R. C. Gore, R. W. Stafford, and V. Z. Williams, Anal. Chem. 20, 402 (1948)

[16] J. W. Linnett, Trans. Faraday Soc. 41, 223 (1945).

[17] G. Herzberg, Infrared and raman spectra of polyatomic molecules (D. Van Nostrand Co., Inc., New York, N. Y., 1945).

[18] H. W. Thompson and P. Torkington, Trans. Faraday Soc. 41, 248 (1945).

[19] N. B. Colthup, J. Opt. Soc. Am. 40, 397 (1950).

[20] H. L. Dinsmore and D. C. Smith, Anal. Chem. 20, 11 (1948).

[21] H. M. Randall, R. G. Fowler, N. Fuson, and J. R. Dangl, Infrared determination of organic structures (D. Van Nostrand Co., Inc., New York, N. Y., 1949).

[22] J. W. Rowen and E. K. Plyler, J. Research NBS 44, 313 (1950) RP2080.

[23] R. Stair and W. W. Coblentz, J. Research NBS 15, 295 (1935) RP830.

Washington, August 11, 1950. 